\title{
ANALISA PENGARUH SISTEM PENDINGIN TERHADAP MESIN BENSIN XENIA TYPE XI 1300 CC 4 SILINDER 16 VALVE ( K3 - DE DOHC )
}

\author{
Wiji.Lestari, Harini \\ Program Studi Teknik Mesin Universitas 17 Agustus 1945 Jakarta
}

\begin{abstract}
ABSTRAK
Untuk mencapai kesempurnaan,sistem temperatur pendingin mesin diperlukan pompa pendingin yang bekerja secara optimal.Apabila pompa pendingin mengalami masalah mengakibatkan sirkulasi air pendingin berkurang sehingga mengakibatkan temperature mesin meningkat dan menyebabkan minyak yang melumasi torak mulai menguap dengan cepat dan torak maupun silinder dapat menyebabkan tegangan berlebihan dan retak atau Tambahan panas yang ditimbulkan melalui gesekan antara berbagai permukaan terutama torak,cincin torak dan dinding silinder.Penelitian ini bertujuan untuk mengetahui seberapa besar pengaruh sistem pendingin terhadap perputaran mesin baik pada saat kondisi pompa normal maupun pada saat kondisi tidak normal. Kapasitas aliran air tawar $\left(\mathrm{Q}_{\mathrm{fw}}\right)$ pada kondisi pompa normal sebesar $0,0005 \mathrm{~m}^{3} /$ menit dengan massa jenis $\rho=971,95 \mathrm{~kg} / \mathrm{m}^{3}$ maka massa aliran air tawar permenit adalah 0,48597 kg/menit. Sedangkan Kapasitas aliran air tawar $\left(\mathrm{Q}_{\mathrm{fw}}\right)$ pada kondisi pompa tidak normal sebesar $0,0003 \mathrm{~m}^{3} /$ menit dengan massa jenis $\rho=968,62 \mathrm{~kg} / \mathrm{m}^{3}$ maka massa aliran air tawar permenit adalah $0,290586 \mathrm{~kg} /$ menit.
\end{abstract}

\section{ABSTRACT}

To achive perfection,the temperature of the engine cooling system is required coolant pump that works optimally, if the coolant pump having problems resulted in the circulation of cooling water is reduced resulting in engine temperature increases and causes the oil to lubricate the piston begins the evaporate quickly and the piston and the cylinder cancause excessive voltage and cranked or additional heat generated through gesrkan between various surfaces especially piston,ring piston and the cylinder wall.This study aims to determine how much influence the cooling system of the engine rotation bath during normal pump conditions or during abnormal conditions freshwater flow capacity of the radiator water at normal pump conditions of $0,0003 \mathrm{~m}^{3} / \mathrm{min}$ then produce freshwater perminute flow periodis $0,290586 \mathrm{~kg} /$ min.

\section{PENDAHULUAN}

Sistem pendingin mesin adalah jenis sistem pendingin tertutup,dimana sistem pendingin dilakukan oleh air pendingin.Panas yang diserap air pendingin kemudian air pendingin bersirkulasi masuk kembali ke sistem pendingin mesin.Sistem pendinginan mutlak diperlukan pada setiap kendaraan,hal ini dimaksudkan untuk mencegah panas yang berlebihan 
pada mesin.Sistem pendinginan air sebagai bahan pendingin adalah air karena sistem pendingin air pendinginannya cukup baik dan tidak menimbulkan suara.

Perpindahan panas yang terjadi pada dinding penukar kaloradalah kombinasi dari perpindahan secara konveksi dan konduksi.Sehingga perpindahan panas yang terjadi disebut dengan perpindahan kalor menyeluruh. perpindahan panas untuk perhitungan jumlah kalor yang di transfer adalah atas dasar besarnya perbedaan menyeluruh temperatur ratarata.Temperatur masuk dan keluar dari radiator dengan kapasitas sesuai pompa yang digunakan untuk sirkulasi, dimana debit sirkulasi air tawar dalam sistem pendingin adalah konstan yaitu $\mathrm{Q}_{\mathrm{fw}}=0,0005 \mathrm{~m}^{3} /$ menit.

\section{Teori Mengenai Sistem Pendinginan Mesin}

Daya poros pada mesin diesel diperoleh melalui pengubahan energi kimia atau nilai kalor bahan bakar.Semakin banyak bahan bakar yang bisa terbakar di dalam ruang bakar,semakin pula daya yang bisa dihasilkan oleh mesin diesel.Semakin besar bahan bakar,maka energi panas yang harus dibuang melalui dinding silinder juga semakin besar.

Pada prinsipnya panas yang diambil dari dinding silinder pada akhirnya akan dibuang ke radiator,

Jadi secara prinsip metode pendinginan mesin dibagi menjadi dua,yaitu :

A. Pendinginan udara langsung

B. Pendinginan tak langsung,yaitu melalui fluida cair.

\section{Proses Perpindahan Panas Pada Silinder Ruang Bakar}

Pada proses perpindahan panas kemampuan pendinginan dari suatu alat pemindah kalor tergantung pada fluida yang mengambil panas dan material dinding penukar kalor.Aliran panas akibat dari hasil pembakaran didalam silinder merambat kedinding silinder dan kemudian dilepas ke fluida pendinginan.

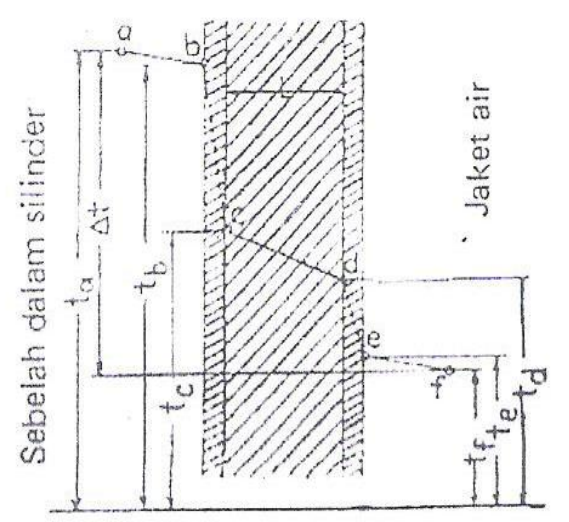

Gambar Aliran panas dari gas panas ke fluida pendinginan. ${ }^{1}$ Wiranto Arismunandar 2002 Motor Bakar Torak 
Keterangan gambar :

Ta $\quad:$ Temperature dibagian dalam silinder

$\mathrm{Tb}-\mathrm{Tc} \quad$ : Adalah penurunan temperature pada lapisan tipis udara

$\mathrm{Tc}-\mathrm{Td} \quad$ : Adalah penutrunan temperature pada dinding silinder

$\mathrm{Td}-\mathrm{Te} \quad$ : Penurunan temperature pada film/lapisan tipis fluida pendingin

Tf : Temperature fluida pendingin

Perbandingan antara besarnya panjang langkah dengan diameter lubang silinder berpengaruh terhadap distribusi panas di dalam elemen-elemen ruang bakar.Adapun pengaruh dari perbandingan tersebut adalah seperti terlihat pada Gambar 4.1

\section{Sistem Pendinginan Pada Konstruksi Mesin}

Untuk menjaga agar tidak terjadi penumpukan panas yang berlebihan (over heating) pada elemen-elemen ruang bakar,maka dilakukan berbagai upaya untuk mendinginkan bagian-bagian mesin seperti : dinding silinder, kepala silinder, katup buang,torak tik dan torak tong.

\section{Sirkulasi Air Untuk Pendinginan Air Jaket}

Jumlah air yang disirkulasi tergantung pada suhu awal dan suhu akhir yang didinginkan dari air. Untuk menghindarkan tegangan panas yang berlebihan.Kalau mesin didinginkan dengan air yang belum mendapat perlakuan kimia,yang selalu mengandung larutan garam dan benda asing lainnya,maka suhu harus dijaga cukup rendah untuk mencegah terjadinya pengendapan kotoran dan timbulnya kerak.

\section{Faktor Pengotoran}

Akibat dari pemakaian fluida untuk sistem pendinginan,maka tidak bisa dihindarkan timbulnya lapisan pengotoran/kerak-kerak pada dinding penukar kalor.Sebagai akibat dari timbulnya pengotoran tersebut maka konduktifitas termal dari dinding penukar kalor menjadi turun,sehingga dapat mengganggu proses perpindahan panas.

\begin{tabular}{|l|l|l|}
\hline \multicolumn{2}{|c|}{ Tabel Data Hasil Perhitungan } \\
\hline & $\begin{array}{l}\text { Faktor pengotoran } \\
\text { R.ft }{ }^{2} .{ }^{0} \text { F/Biu }\end{array}$ & $M^{3} .{ }^{0} \mathrm{C} W$ \\
\hline Air laut, dibawah $125^{\circ} \mathrm{F}$ & 0,0005 & 0,00009 \\
\hline Di atas $125^{0} \mathrm{~F}$ & 0,003 & 0,0005 \\
\hline Air sirkulasi AC & 0,001 & 0,0002 \\
\hline Air tawar biasa & 0,002 & 0,0006 \\
\hline Minyak pelumas & 0,005 & 0,0009 \\
\hline
\end{tabular}




\section{Data Water pump :}

1. Jenis Pompa

: Sentrifugal

2. Kapasitas

: $0,0005 \mathrm{~m}^{3} /$ menit

3. Tekanan

$: 1,0 \mathrm{~kg} / \mathrm{m}^{3}$

4. Putaran

$: 850 \mathrm{rpm}$

5. Head Terpasang

: $0,3 \mathrm{~m}$

6. Diameter pipa

$: 11,5 \mathrm{~mm}$

\section{Alat-alat yang digunakan}
a. Flow meter : Alat ini digunakan untuk mengukur aliran air dalam pipa.
b. Manometer : Alat ini digunakan untuk mengukur tekanan air dalam pipa.
c. Thermometer : Alat ini digunakan untuk mengukur temperature mesin.

\section{Prosedur Pengujian :}

Langkah yang harus dilakukan dalam pengujian alat ini adalah sebagai berikut :

1. Menghidupkan saklar utama (Switch on/off)

2. Mengatur putaran pompa sehingga menunjukkan putaran $850 \mathrm{Rpm}$ pada tachometer.

3. Menungu hingga aliran pendinginan dan putaran pompa tetap $850 \mathrm{Rpm}$.

4. Membaca dan mencatat beda ketinggian air pada manometer.

5. Mengulangi prosedur 4 sebanyak 5 kali dengan selang waktu 1 menit.

\section{Skema sistem pendingin pada mesin}

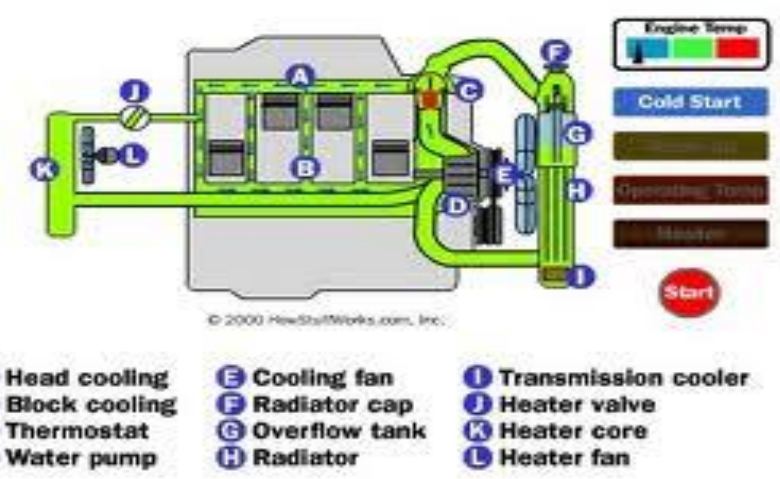

Gambar skema sistem pendingin pada mesin

\section{DATA HASIL DAN PEMBAHASAN}

\section{Data Mesin}

Data-data mesin yang digunakan dalam penelitian ini adalah :

Jenis/ Tipe Mesin : K3-VE, DOHC, VVT-i (Valve Variable Timing - intelligent)

1. Kapasitas Silinder

: 1298 cc

2. Daya Maksimum

: 92/6000 ps/rpm

3. Torsi Maksimum

: $12.2 / 4400 \mathrm{kgm} / \mathrm{rpm}$

4. Perbandingan Kompresi

$:(10: 1)$

5. Sistem Pembakaran

: Electronic Fuel Injection

6. Bahan Bakar

: Gasoline 
7. Kapasitas Bahan Bakar

8. Tipe Transmisi

\section{Pompa Air Tawar / Air Jacket}

1. Jenis Pompa

2. Kapasitas

3. Tekanan

4. Putaran

5. Head Terpasang

6. Diameter pipa
: $45 \operatorname{ltr}$

: 5 Speed Manual

\section{Data Hasil Penelitian}

A. Temperatur air pendingin pada kondisi pompa normal Dengan kapasitas aliran 0,0005 $\mathrm{m}^{3} /$ menit.

\begin{tabular}{|c|c|c|}
\hline \multirow{2}{*}{ No } & \multicolumn{2}{|c|}{ Temperatur $\left({ }^{\circ} \mathrm{C}\right)$} \\
\cline { 2 - 3 } & Masuk Mesin $\left(\mathrm{T}_{1}\right)$ & Keluar Mesin $\left(\mathrm{T}_{2}\right)$ \\
\hline 1 & 80 & 84 \\
\hline 2 & 81 & 85 \\
\hline 3 & 81 & 85 \\
\hline 4 & 80 & 84 \\
\hline 5 & 81 & 85 \\
\hline Rata-rata & 80,6 & 84,6 \\
\hline
\end{tabular}

B. Temperatur air pendingin pada kondisi pompa tidak normal Dengan Kapasitas aliran $0,0003 \mathrm{~m}^{3} /$ menit.

\begin{tabular}{|c|c|c|}
\hline \multirow{2}{*}{ No } & \multicolumn{2}{|c|}{ Temperatur ${ }^{\circ} \mathrm{C}$} \\
\cline { 2 - 3 } & Masuk Mesin $\left(\mathrm{T}_{1}\right)$ & Keluar Mesin $\left(\mathrm{T}_{1}\right)$ \\
\hline 1 & 80 & 87 \\
\hline 2 & 81 & 90 \\
\hline 3 & 81 & 90 \\
\hline 4 & 80 & 87 \\
\hline 5 & 81 & 90 \\
\hline Rata-rata & 80,6 & 88,9 \\
\hline
\end{tabular}




\section{Perhitungan Panas Pada Kondisi Pompa Normal Dengan Kapasitas 0,0005 $\mathbf{m}^{3} /$ menit.}

Besarnya energi panas yang dilepas dari dinding silinder ke air jacket dapat diperoleh dari persamaan berikut :

$$
\mathrm{Q}_{\mathrm{fw}} \quad=\text { M.Cp. AT. }
$$

(L.A. de bruijn dan muilwijk "MOTOR BAKAR" hal 95)

Dimana :

$\mathrm{Q}_{\mathrm{fw}} \quad=$ Energi panas yang dilepas ke Air Jacket $(\mathrm{kJ} /$ menit $)$

$\mathrm{m} \quad=$ Massa aliran air jacket $(\mathrm{kg} / \mathrm{jam})$

$\mathrm{Cp}=$ Kapasitas panas rata-rata $\left(\mathrm{kJ} / \mathrm{kg}{ }^{\circ} \mathrm{C}\right)$ pada temperatur rata- rata air tawar

$\Delta \mathrm{T}=$ Selisih temperatur fluida (air jacket) masuk dan keluar dari Radiator $\left({ }^{\circ} \mathrm{C}\right.$ ) Maka :

Temperatur rata-rata air jacket $\left(\mathrm{T}_{\mathrm{fw}}\right)$

$$
\mathrm{T}_{\mathrm{fw}} \text { rata-rata }=\frac{T_{1}+T_{2}}{2}
$$

Dimana :

- Kapasitas aliran $0,0005 \mathrm{~m}^{3} / \mathrm{menit}$

- Temperatur rata-rata air masuk ke Fw. Cooler $\left(\mathrm{T}_{1}\right) 80,6{ }^{\circ} \mathrm{C}$

- Temperatur rata-rata air keluar dari Fw. Cooler $\left(\mathrm{T}_{2}\right) 84,6{ }^{\circ} \mathrm{C}$

$$
\mathrm{T}_{\mathrm{fw}} \text { rata-rata }=\frac{80,6+84,6}{2}=82,6^{\circ} \mathrm{C}
$$

Kapasitas panas air pada temperatur $82,6{ }^{\circ} \mathrm{C}$ dapat diperoleh dengan cara sebagai berikut :

Dari daftar sifat air dari lampiran diperoleh dengan sistem interpolasi sbb:

- Kapasitas panas (Cp) pada temperatur $76,67^{\circ} \mathrm{C}$ adalah $4,191 \mathrm{~kJ} / \mathrm{kg}{ }^{\circ} \mathrm{C}$

- Kapasitas panas (Cp) pada temperatur $82,22^{\circ} \mathrm{C}$ adalah $4,195 \mathrm{~kJ} / \mathrm{kg}{ }^{\circ} \mathrm{C}$

Maka kapasitas panas (Cp) pada temperatur $82,6{ }^{\circ} \mathrm{C}$ adalah :

$$
\begin{aligned}
\mathrm{C}_{\mathrm{p}} & =4.191+\frac{(82,6-76,67)}{(82,22-76,67)}(4,195-4,191) \\
& =4,194 \mathrm{~kJ} / \mathrm{kg} .{ }^{\circ} \mathrm{C}
\end{aligned}
$$

- Massa jenis ( $\rho$ ) Pada temperatur $76,67{ }^{\circ} \mathrm{C}, \rho=973,7 \mathrm{~kg} / \mathrm{m}^{3}$

- Massa jenis ( $\rho$ ) Pada temperatur $82,22{ }^{\circ} \mathrm{C}, \rho=970,2 \mathrm{~kg} / \mathrm{m}^{3}$

Maka massa jenis $(\rho)$ pada temperatur rata-rata $82,6{ }^{\circ} \mathrm{C}$

$$
\begin{aligned}
\rho & =970,2+\frac{(82,6-76,67)}{(82,22-76,67)}(970,2-973,7) \\
& =971,95 \mathrm{~kg} / \mathrm{m}^{3}
\end{aligned}
$$

Massa aliran air tawar permenit dapat diperoleh dengan persamaan :

$$
\mathrm{m}=\mathrm{Q}_{\mathrm{fw}} \times \rho
$$

dimana :

$$
\mathrm{m} \quad=\text { massa aliran air jacket }(\mathrm{kg} / \mathrm{jam})
$$


$\mathrm{Q}_{\mathrm{fw}} \quad=$ Energi panas yang dilepas ke Air Jacket $(\mathrm{kJ} / \mathrm{menit})$

$\rho \quad=$ massa jenis $\left(\mathrm{kg} / \mathrm{m}^{3}\right)$

Maka massa aliran air tawar permenit pada temperatur rata-rata $82,6{ }^{0} \mathrm{C}$ adalah :

$\mathrm{m}=0,0005 \mathrm{~m}^{3} /$ menit $\times 971,95 \mathrm{~kg} / \mathrm{m}^{3}$

$=0,48597 \mathrm{~kg} / \mathrm{menit}$.

Cp adalah kapasitas panas pada temperatur rata-rata adalah $4,191 \mathrm{~kJ} / \mathrm{kg}{ }^{\circ} \mathrm{C}$

$\Delta \mathrm{T}$ adalah selisih temperatur rata-rata $=82,22-76,67=5,55{ }^{\circ} \mathrm{C}$

Maka Besarnya energi panas yang dilepas dari dinding silinder ke air jacket

$\mathrm{Q}_{\mathrm{fw}} \quad=0,48597 \mathrm{~kg} /$ menit $\times 4,191 \mathrm{~kJ} / \mathrm{kg}{ }^{\circ} \mathrm{C} \times 5,55^{\circ} \mathrm{C}$

$=11,3068 \mathrm{~kJ} /$ menit.

Perhitungan Panas Pada KondisiPompa Tidak Normal Dengan Kapasitas 0,0003 $\mathbf{m}^{3} /$ menit.

Besarnya energi panas yang dilepas dari dinding silinder ke air jacket dapat diperoleh dari persamaan berikut :

$$
\mathrm{Q}_{\mathrm{fw}}=\mathrm{m} . \mathrm{Cp} . \mathrm{AT}
$$

Dimana :

$\mathrm{m} \quad=$ Massa aliran air jacket $(\mathrm{kg} / \mathrm{jam})$

$\mathrm{Cp}=$ Kapasitas panas rata-rata $\left(\mathrm{kJ} / \mathrm{kg}^{\circ} \mathrm{C}\right)$ pada temperatur rata- rata air tawar

$\Delta \mathrm{T}=$ Selisih temperatur fluida (air jacket) masuk dan keluar dari Radiator $\left({ }^{\circ} \mathrm{C}\right)$

Maka :

Temperatur rata-rata air jacket $\left(\mathrm{T}_{\mathrm{fw}}\right)$

$\mathrm{T}_{\mathrm{fw}}$ rata-rata $\quad=\frac{T_{1}+T_{2}}{2}$

Dimana :

- Kapasitas aliran $0,0003 \mathrm{~m}^{3} /$ menit

- Temperatur rata-rata air masuk ke Fw. Cooler $\left(\mathrm{T}_{1}\right) \quad 80,6{ }^{\circ} \mathrm{C}$

- Temperatur rata-rata air keluar dari Fw. Cooler $\left(\mathrm{T}_{2}\right) \quad 88,9{ }^{\circ} \mathrm{C}$

$\mathrm{T}_{\mathrm{fw}}$ rata-rata $\quad: \frac{80,6+88,9}{2}=84,75^{\circ} \mathrm{C}$

Kapasitas panas air pada temperatur $84,75{ }^{\circ} \mathrm{C}$ dapat diperoleh dengan cara sebagai berikut :

Dari daftar sifat air dari lampiran diperoleh dengan sistem interpolasi sbb:

- Kapasitas panas (Cp) pada temperatur $82,22{ }^{\circ} \mathrm{C}$ adalah $4,195 \mathrm{~kJ} / \mathrm{kg}{ }^{\circ} \mathrm{C}$

- Kapasitas panas (Cp) pada temperatur $87,78{ }^{\circ} \mathrm{C}$ adalah $4,199 \mathrm{~kJ} / \mathrm{kg}{ }^{\circ} \mathrm{C}$

- Kapasitas panas (Cp) pada temperatur $84,75{ }^{\circ} \mathrm{C}$ adalah sebagai berikut :

- Selisih temperatur $(\Delta \mathrm{T})=87,78-82,22=5,56^{\circ} \mathrm{C}$

- Selisih nilai kapasitas panas $(\Delta \mathrm{Cp})=4,199-4,195=0,003 \mathrm{~kJ} / \mathrm{kg}^{\circ} \mathrm{C}$

Sehingga pada setiap kenaikan $5,56{ }^{\circ} \mathrm{C}$ kanaikan $\mathrm{cp}$ adalah $=$ 


$$
\frac{0,003}{5,56}=5,4 \times 10^{-4} \mathrm{~kJ} / \mathrm{kg}^{\circ} \mathrm{C}
$$

Maka pada temperatur $84,75{ }^{\circ} \mathrm{C}$ diperoleh $\mathrm{Cp}$

$$
\begin{aligned}
\mathrm{Cp} & =4,195+(84,75-82,22) \times\left(5,4 \times 10^{-4} \mathrm{~kJ} / \mathrm{kg}^{\circ} \mathrm{C}\right) \\
& =4,196 \mathrm{~kJ} / \mathrm{kg}^{\circ} \mathrm{C}
\end{aligned}
$$

Sehingga energi panas yang dikeluarkan mengalami air jacket per jam, adalah

$\mathrm{Q}_{\mathrm{fw}}=\mathrm{m} \times \mathrm{Cp} \times \Delta \mathrm{T} \mathrm{kJ} / \mathrm{jam}$.

Dimana :

$\mathrm{m}=$ massa aliran air tawar $(\mathrm{kg} / \mathrm{menit})$

Kapasitas aliran air tawar $\left(\mathrm{Q}_{\mathrm{fw}}\right)=0,0003 \mathrm{~m}^{3} /$ menit dengan massa jenis $(\rho$ ) Pada temperatur $84,75{ }^{\circ} \mathrm{C}$ diperoleh dengan interpolasi sebagai berikut :

Pada temperatur $82,22{ }^{0} \mathrm{C}, \quad \rho=970,22 \mathrm{~kg} / \mathrm{m}^{3}$

Pada temperatur $87,78^{0} \mathrm{C}, \rho=966,7 \mathrm{~kg} / \mathrm{m}^{3}$

Untuk temperatur rata-rata $84,75^{\circ} \mathrm{C}$

$$
\begin{aligned}
\rho & =970,22+\frac{(84,75-82,22)}{(87,79-82,22)}(966,7-970,22) \\
& =968,62 \mathrm{~kg} / \mathrm{cm}^{2}
\end{aligned}
$$

maka massa aliran air tawar permenit adalah :

$$
\begin{aligned}
\mathrm{m} & =\mathrm{Q}_{\mathrm{fw}} \times \rho \\
& =0,0003 \mathrm{~m}^{3} / \text { menit } \times 961,02 \mathrm{~kg} / \mathrm{m}^{3} \\
& =0,290586 \mathrm{~kg} / \text { menit. }
\end{aligned}
$$

- $\mathrm{Cp}$ adalah kapasitas panas pada temperatur rata-rata adalah $4,196 \mathrm{~kJ} / \mathrm{kg}^{\circ} \mathrm{C}$.

- $\Delta \mathrm{T}$ adalah selisih temperatur rata-rata $\left({ }^{0} \mathrm{C}\right)$

$\Delta \mathrm{T} \quad=87,79-82,22=5,57^{\circ} \mathrm{C}$

Maka Besarnya energi panas yang dilepas dari dinding silinder ke air jacket

$\mathrm{Q}_{\mathrm{fw}}=0,290586 \mathrm{~kg} / \mathrm{menit} \times 4,196 \mathrm{~kJ} / \mathrm{kg}{ }^{\circ} \mathrm{C} \times 5,57^{\circ} \mathrm{C}$

$=6,7914 \mathrm{~kJ} /$ menit.

\section{KESIMPULAN DAN SARAN}

\section{Kesimpulan}

Dari hasil perhitungan maka dapat disimpulkan sebagai berikut :

1. Energi panas yang di keluarkan atau di lepas dari dinding silinder melalui sistem pendingin dengan menggunakan air radiator pada kondisi pompa normal 11,3068 $\mathrm{kJ} /$ menit dan kondisi pompa tidak normal adalah $6,7914 \mathrm{~kJ} / \mathrm{menit}$

2. Kapasitas aliran air tawar dari air radiator pada kondisi pompa normal sebesar 0,0005 $\mathrm{m}^{3} /$ menit maka menghasilkan masa aliran air tawar permenit adalah 0,48597 $\mathrm{kg} /$ menit, sedangkan Kapasitas aliran air tawar dari air radiator pada kondisi pompa 
normal sebesar $0,0003 \mathrm{~m}^{3} /$ menit maka menghasilkan masa aliran air tawar permenit adalah $0,290586 \mathrm{~kg} / \mathrm{menit}$.

\section{Saran}

Sistem pendinginan mesin merupakan bagian yang penting pada pengoperasian mesin diesel, oleh karenanya diperlukan perawatan yang baik. Agar kemampuan pendingin dari fresh water cooler tetap optimal, maka penulis menyarankan sebagai berikut:

1. Dilakukan pembersihan dinding penukar kalor secara terjadwal untuk menghindari menurunnya konduktifitas thermal akibat terjadinya pengotoran.

2. Gunakan kualitas air pendingin yang baik salah satunya adalah air hasil sirkulasi AC.

3. Periksa temperatur-temperatur air tawar yang keluar dari fresh water cooler agar dapat terdeteksi adanya gangguan pada sistem pendinginan.

\section{DAFTAR PUSTAKA}

Frank Kreith, Arko Prijono, “Prinsip-prinsipPerpindahan Panas”, Erlangga, Jakarta.2000

Maleev, terjemahan Bambang Priambodo, "Operasi dan Pemeliharaan Mesin Diesel", Erlangga, Jakarta, 2009

Pudjanarsa A, Nursuhud Djati. (2008), Mesin Konversi Energi, Penerbit Andi, Yogyakarta.

Lemigas (2000). Dasar-Dasar Pompa Positive Displacement dan Centrifugal,Lemigas, Jakarta.

Daryanto,2010.Reparasi Mobil Bensin. PT.Prestasi pustakaraya.Jakarta

Astu Pudjanarsa, Djati Nursuhud "MESIN KONVERSI ENERGI” Penerbit Andi Yogyakarta 2006

Harsanto “MOTOR BAKAR”. Penerbit Djambatan, Jakarta, 2002

L.A. de bruijn dan muilwijk "MOTOR BAKAR". Penerbit Bhatara Karya Aksara, Jakarta.

Holman, terjemahan jasifi, “PERPINDAHAN KALOR”,Erlangga,Jakarta. 